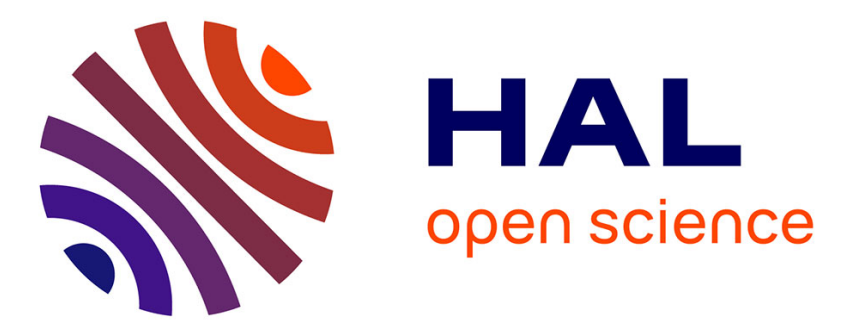

\title{
Comparative Study of PMSM and SRM Capabilities
}

Abdelkader Lebsir, Ammar Bentounsi, Redjem Rebbah, Soltane Belakehal,

Mohamed Benbouzid

\section{To cite this version:}

Abdelkader Lebsir, Ammar Bentounsi, Redjem Rebbah, Soltane Belakehal, Mohamed Benbouzid. Comparative Study of PMSM and SRM Capabilities. IEEE POWERENG 2013, May 2013, Istanbul, Turkey. pp.760-763. hal-00926304

\section{HAL Id: hal-00926304 https://hal.science/hal-00926304}

Submitted on 9 Jan 2014

HAL is a multi-disciplinary open access archive for the deposit and dissemination of scientific research documents, whether they are published or not. The documents may come from teaching and research institutions in France or abroad, or from public or private research centers.
L'archive ouverte pluridisciplinaire HAL, est destinée au dépôt et à la diffusion de documents scientifiques de niveau recherche, publiés ou non, émanant des établissements d'enseignement et de recherche français ou étrangers, des laboratoires publics ou privés. 


\section{Comparative Study of PMSM and SRM Capabilities}

\author{
A. Lebsir, A. Bentounsi, R. Rebbah and S. Belakehal \\ LGEC, Dept. of Electrotechnics \\ University of Constantine 1 \\ Constantine, Algeria \\ E-mail: lebkadersa@gmail.com
}

\author{
M.E.H. Benbouzid \\ University of Brest, EA 4325 LBMS \\ Brest, France \\ E-mail: Mohamed.Benbouzid@univ-brest.fr
}

\begin{abstract}
This paper is a synthesis of various research work performed on innovative structures for electrical machines (EM) responding to new performance requirements and applications. A presentation of the various statistical applications of EM will be made with various criteria. It will establish an initial comparison between the possibilities of both types of machines, namely the permanent magnet synchronous machine (PMSM) and switched reluctance machine (SRM), since more competing by conventional machines such as induction machines. It will be completed by a performance comparison study using a torque density criterion. Finally, an analytical-numerical method for PMSM and SRM structures design will be proposed.
\end{abstract}

Keywords-PMSM, SRM, specific applications, design, sizing.

\section{INTRODUCTION}

The progress achieved during the last two decades in magnetic materials, electronic devices, calculation methods and other software simulations have enabled designers to improve the performance and costs of electric machines (EM). This is particularly the case of conventional machines such as synchronous machines and induction machines (IM) although innovative structures such as permanent magnet synchronous machine (PMSM) and switched reluctance machine (SRM) for special applications (wind generators, EV ...) [1-11]. A comparative study between different types of machines is complicated but remains a challenge. Thus, different approaches have been proposed, the most famous being the "sizing equation" [12-20].

The aim of this paper is to contribute to this issue, thanks to a comparative study in two steps. We begin by presenting the results of a literature review on the application areas as statistics. Then, we focus on a comparative study of performances, in terms of torque density, of two topologies of machines: a radial flux PMSM and a doubly salient SRM machines for a direct drive wind generator as shown in Fig. 1.

\section{COMPARISON OF ELECTRIC MACHINES APPLICATIONS}

To make the comparison, we have to validate a maximum of analogies between these two machines, as follows:

- Geometric analogies: the dimensions of the base are the outer diameter $D_{o}$ of the stator and the effective stack length $L$.

- Electric analogies: functioning mode and power.

- Mechanical analogies: linear or rotating architectures.

- Thermal analogies: operating temperature.
Many studies are interested in the comparison between the electric machines in order to focus on the most adaptable device for the current application. On the basis of these studies, we have established a first list of criteria for the comparison, as follows:

- Performances: torque, power density, efficiency.

- Cost: machine and converter.

- Reliability: maintenance, fault tolerance.

- Applications: EV, aerospace, wind generators ...

In matters of the comparison of the electric machines (EM) for different applications, the bibliographic research that we have done allowed us to establish some statistics as shown in Fig. 2 [1-14].

\section{A. Electric Vehicle Application}

The literature shows that there is a great deal of works concerning the comparison of the different structures for the electric vehicle applications (EV). These last ones prefer a motorization of big effectiveness, size, low cost and more faulttolerant [1-8]. Definitely, as the statistics shown in figure 3 indicate, this is a switched reluctance machine (SRM) that fits this type of application.

\section{B. Wind Generator Application}

The wind power systems convert the wind energy to an electric energy and make a part of the sources of renewable energies as an alternative to the conventional sources of energy. The choice of the type of aero-generators depends on several criteria, depending on the level of force or charge that we want to give to the network. The asynchronous generators are widely used, but they have plenty of maintenance problems and have a very weak efficiency. On the other hand, the synchronous generators are more expensive because of the presence of permanent magnet in them. This has permitted an eventual utilization switched reluctance generators (SRG), which is characterized by simple structure, robustness, low cost, absence of a speed multiplication system [9-10].

\section{Aerospace Application}

An application that is less tolerant for break downs and high performances, many studies were carried out on (PMSM) and the (SRM) [11-12]. These studies used analytical and numerical models to simulate the different problems that might occur in the machine and its power converter in order to make a diagnosis. 


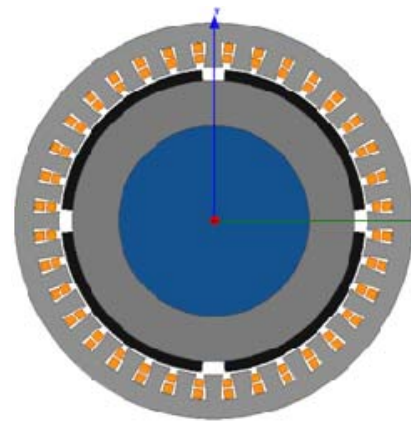

(a) PMSM

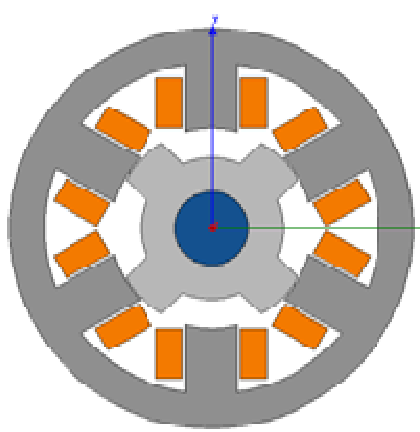

(b) SRM
Figure 1. Cross section of the studied machines.

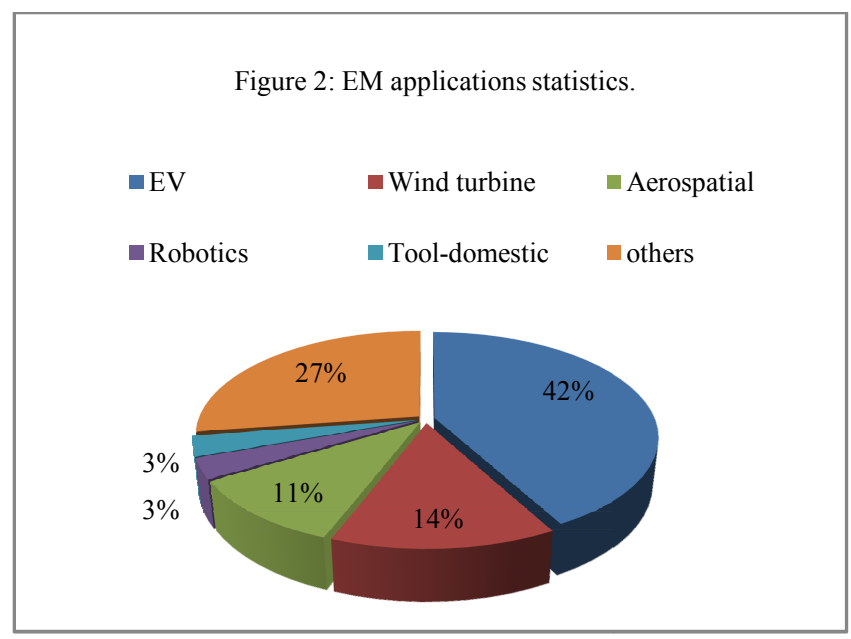

Figure 3. EV applications statistics.

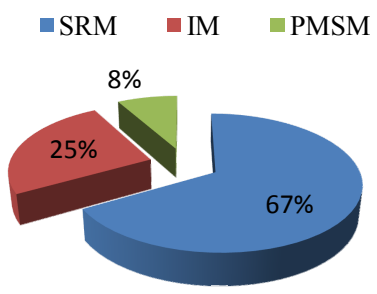

\section{Special Applications}

The choice of a machine for an application is a delicate problem because it needs a great number of parameters to be taken into account. Indeed, the machine might be costeffective, light, a bit cumbersome, with a good efficiency, etc. The PMSM is without doubt the best candidate in terms of efficiency, power and mass density, and dynamic performance. in this context, PMSMs are the best choice for robotics and appliances applications [13-15].

From the studied papers, we derived Table 1 that classifies the most suited machines for each application. We deduce that the PMSM presents a relatively good choice.
TABLE I. COMPRATIVE APPLICATIONS OF EM

\begin{tabular}{|l|c|c|c|}
\cline { 2 - 4 } \multicolumn{1}{c|}{} & $\boldsymbol{I M}$ & PMSM & SRM \\
\hline EV & 2 & 1 & 5 \\
\hline Wind generator & 5 & 4 & 3 \\
\hline Aerospace & 2 & 4 & 3 \\
\hline Robotics & 1 & 5 & 2 \\
\hline Tool-domestic & 1 & 4 & 2 \\
\hline Others & 3 & 4 & 3 \\
\hline
\end{tabular}

\section{COMPARISON OF PMSM AND SRM PERFORMANCE}

Comparison of the performances generated by different machine topologies has been an interesting subject for study. The $D^{2} L$ sizing equation is a well known formula that relates the output power $P_{o}$ and the synchronous speed $\Omega_{s}$ to the air gap volume. In 1987, Honsinger proposed a sizing equation for induction machines [16]. This approach provides good results only for small pole numbers. Partly based on Honsinger's study and by introducing some improvements, the sizing procedure proposed by Huang et. al in 1998 is utilized to compare the capability of different machines topologies such as doubly salient permanent magnet machines and IM [17]. In 2002, Huang et. al developed a general approach for performance evaluation in terms of torque density and efficiency of both radial, axial and transverse flux machines [18].

The proposed paper focuses on comparative performances in terms of power density of the two studied machines, a radial flux surface mounted PMSM machine and a doubly salient SRM machine, using sizing approach less complex than the preceding ones.

\section{A. Sizing Equations for PMSM}

The peak value of the phase air gap EMF for the fundamental is given by:

$$
\widehat{E_{1}}=N_{t} k_{w 1} \omega \widehat{\emptyset}_{1}
$$

where $N_{t}$ is the number of turns per phase, $k_{w l}$ is the winding distribution factor, $\omega=p \Omega$ is the electric pulsation related to the number of pole pairs $p$ and the angular speed $\Omega, \widehat{\emptyset}$ is the peak value of the magnetic flux per pole produced by the magnets and which is expressed as:

$$
\widehat{\emptyset}_{1}=\widehat{B}_{g 1} L \tau_{p}
$$

where $\widehat{B}_{g 1}$ is the fundamental air gap flux density, $L$ is the effective stack length, $\tau_{p}=\pi D / 2 p$ is the pole pitch, $D$ is the stator inner diameter (air gap diameter).

The fundamental air gap flux density is related to the flux density above the magnets $B_{m}$ and to the half pole angle $\alpha$ (this angle is normally chosen close to $\pi / 3$ ) by the formula:

$$
\hat{B}_{g 1}=\left(\frac{4}{\pi}\right) B_{m} \sin \alpha
$$

The peak value of the phase current is given by:

$$
\hat{I}_{1}=\hat{A}_{1} \pi D / 2 N_{t} m_{1}
$$

where $\hat{A}_{1}$ is the peak current loading and $m_{l}$ is the number of stator phases. 
Knowing that the expression of the $\mathrm{m}_{1}$-phase output power is:

$P_{P M S M}=\eta_{1}\left(\frac{m_{1}}{2}\right) \hat{E}_{1} \hat{I}_{1} \cos \varphi_{1}$

where $\eta_{I}$ is the efficiency and $\cos \varphi_{I}$ is the power factor.

By combining the precedent equations, one can rearrange (5):

$P_{P M S M}=\eta_{1}\left(\frac{\pi^{2}}{8}\right) k_{w 1} \hat{B}_{\mathrm{g} 1} \hat{A}_{1} \mathrm{D}^{2} \mathrm{~L} \Omega \cos \varphi_{1}$

\section{B. Sizing Equations for SRM}

The power developed by a SRM is given by [19]:

$$
P_{S R M}=\eta k_{d} k_{1} k_{2} A_{s} B N_{r} D^{2} L \cos \varphi
$$

where $\eta$ is the efficiency, $k_{d}$ is the duty cycle, $k_{l}$ is a constant, $k_{2}$ depends on aligned saturated and unaligned inductances, $A_{s}$ is the specific electric loading, $B$ is the stator pole flux density at the aligned position, $N_{r}$ is the rotor speed (rpm), $D$ is the bore diameter and $L$ is the active axial length.

$$
k_{1}=\left(\frac{\pi^{2}}{120}\right)
$$

In general, the range of $k_{2}$ is given by:

$$
0.65<k_{2}<0.75
$$

The specific electric loading is defined as:

$$
A_{s}=2 N_{t} i m / \pi D
$$

where $N_{t}$ is the number of turns per stator phase excited by the current $i$ and $m$ is the number of phases conducting simultaneously (in our case, only one phase conducts at a time, thus: $m=1$ ).

By introducing the angular speed $\Omega(\mathrm{rad} / \mathrm{sec})$, (7) can be rearranged:

$$
P_{S R M}=\eta k A_{S} B D^{2} L \Omega \cos \varphi
$$

By fixing the values of the coefficients at: $k_{d}=1$ and $k_{2}=0.75$ one deduces the value of the global coefficient: $k=3 \pi / 16$

\section{Performance Comparison}

By using the ratio $\mathrm{T}=\left(\mathrm{P} / \mathrm{D}^{2} \mathrm{~L} \Omega\right)$ which represent the criterion torque density:

- for the PMSM, one can deduce from (6) :

$$
T_{P M S M}=\left(\frac{\pi^{2}}{8}\right) k_{w 1} C_{P M S M}\left(\widehat{B}_{\mathrm{g} 1}, \hat{A}_{1}, \eta_{1}, \cos \varphi_{1}\right)
$$

- for the SRM, one can deduce from (11):

$$
T_{S R M}=k C_{S R M}\left(B, A_{s}, \eta, \cos \varphi\right)
$$

the relative torque density ratio $\rho_{T}$ between both machines topologies may be calculated if the linear current density $A$ and the air gap flux density $B$ are the same for both machines PMSM and SRM:

$$
\begin{aligned}
& \rho_{T}=\frac{T_{P M S M}}{T_{S R M}}=\left(\frac{\pi^{2}}{8}\right)\left(\frac{k_{w 1}}{k}\right)\left(\frac{\eta_{1} \cos \varphi_{1}}{\eta \cos \varphi}\right) \\
& \rho_{T}=1.88\left(\frac{\eta_{1} \cos \varphi_{1}}{\eta \cos \varphi}\right)
\end{aligned}
$$

Although equation (15) indicates a relative superiority of the PMSM, one cannot deduce any conclusion without calculating the losses and the power factors of both machines. The first step is an analytical design followed by an accurate determination of the losses by numerical approach such as finite element method (FEM). The second step is to optimize geometrical structures and to evaluate the costs of the machines associated with their converters [20].

\section{DESIGN METHODOLOGIES}

To be able to choose the most adaptable machine for this given application, we have first to pre-dimension the most adaptable topology for the imposed charges. Generally, the design of a rotating electric machine goes through a step of analytical calculation that gives a first result which can be refined after a second step done with numerical simulations. The design of electric machines stays as an essential part in the realization of electromechanical devices. The power of calculators, the precision of the numerical method used as a visual quality of the work interface under specific software cannot substitute the approach analytical as for its determination of the geometric and the electromagnetic parameters of the electrical machine. Usually, we prefer to associate the two approaches, which lead to an analyticalnumerical approach.

\section{A. Design Methodology of PMSM}

The PMSM are widely used and their functioning is better known. They are generally composed of two parts; one is stator that contains the slots in which there are the phase's conductors, while the other is a rotor one which contains the permanent magnets. For their design, an analytical model was developed, which is contains a certain number of entrance parameters that make in relation the geometric and magnetic robustness of the machine with a level of hypothesis. These simplified formulations are generally sufficient because they are well adapted for the studied structure; however, they tend to lose in precision because of the unusual design. Fig. 5 illustrates the steps of the prototype design on the basis of the hypothesis and the entrance parameters of the model.

\section{B. Design Methodology of SRM}

In comparison with the PMSM, the SRM is simpler. Its stator contains the teeth which constitute the poles and support the windings; its rotor is usually passive (no windings, no magnets). The diagram of the different steps is depicted in Fig. 6.

The second step usually calls the numerical model and the basic physical equations of the machine which are resolved with a weak level of hypothesis that permits taking into account the electric, magnetic, mechanical, and thermal phenomena. 


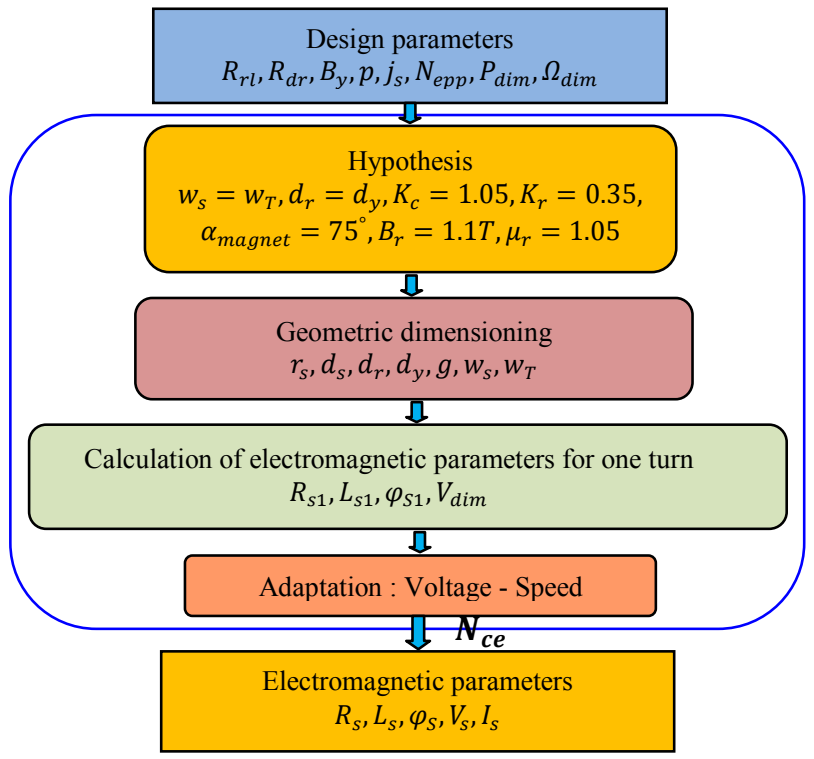

Fig.5: Diagram dimensioning the PMSM.

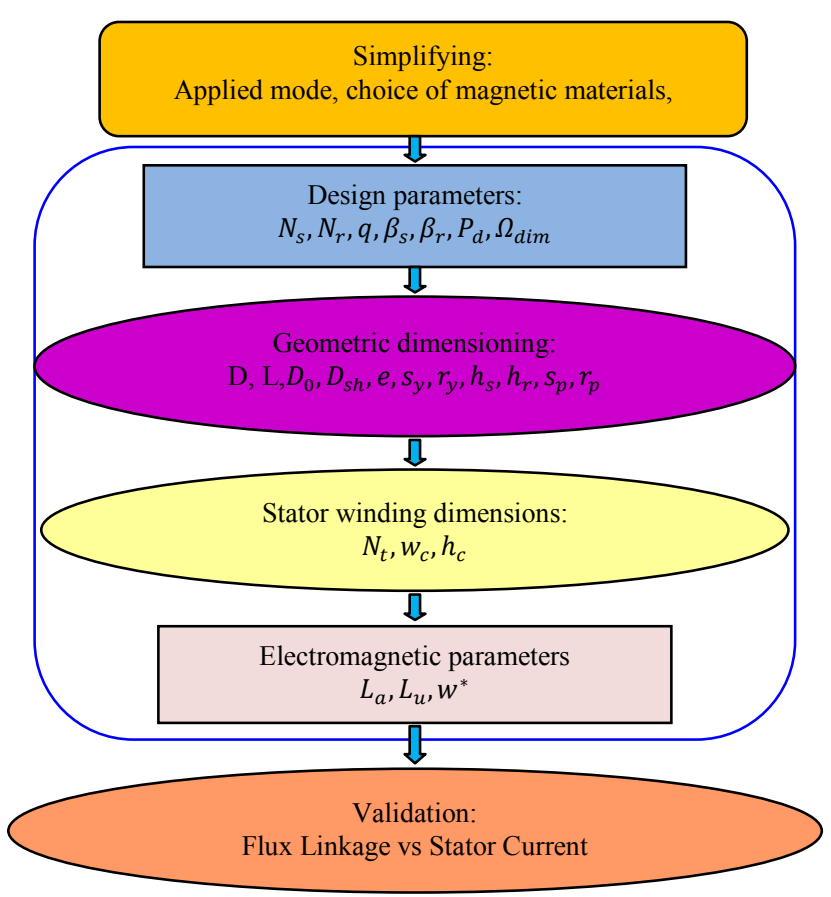

Fig. 6: Diagram dimensioning the SRM

\section{CONCLUSION}

This work presents a state of the art on the research works that are currently performed on the diverse types of electric machines and their applications. Many works have given comparisons to resolve the problem of choice of the most adaptable machine for application in a particular environment. The PMSM and SRM proved to be good candidates, regarding the recent developments in their materials, control systems and the new emphasis that necessitates particular conditions of functioning. According to the literature, their performances lead to the first step, which is the calculation of the dimensioning and the design of the entire systems (machine and converter) in order to get the desired performances. Finally we can conclude from the sizing equations of the two machines PMSM can be smaller than SRM in the same value of rotation speed and output power.

\section{REFERENCES}

[1] J. M. Kokernak and D. A. Torrey, "Motor Drive Selection for Automotive Applications", ICEM2002.

[2] N. Hashernnia and B. Asaei, "Comparative Study of Using Different Electric Motors in the Electric Vehicles“, Proceedings of ICEM'2008.

[3] M. Zeraoulia, M. E. H. Benbouzid, and D. Diallo, "Electric Motor Drive Selection Issues for HEV Propulsion Systems: A Comparative Study“, IEEE Transactions on Vehicular Technology, vol. 55, No. 6, November 2006.

[4] K. M. Rahman, B. Fahimi, G. Suresh, A. V. Rajarathnam and M. Ehsani, "Advantages of Switched Reluctance Motor Applications to EV and HEV: Design and Control Issues“, IEEE Trans.On Industry Applications, vol. 36, No. 1, January/February 2000.

[5] S. Wang, Q. Zhan, Z. Ma, and L. Zhou, "Implementation of a 50-kw four-phase switched reluctance motor drive system for HEV“, IEEE Trans.On Magnetics, vol. 41, No. 1, January 2005.

[6] J. G.W. West, "DC, induction, reluctance and PM motors for electric vehicles“, Power Engineering Journal, vol. 8, no. 2, April 1994.

[7] X. D. Xue, K. W. E. Cheng, and N. C. Cheung, "Selection of Electric Motor Drives for Electric Vehicles“, 2008 Australasian Universities Power Engineering Conference (AUPEC'08).

[8] K. Ogawa, N. Yamamura, and M. Ishda, "Study for small size wind power generatingsystem using switched reluctance generator", IEEEICIT2006, 15-17 Dec. 2006, pp. 1510-1515.

[9] D. G. Dorrell, and M. Jovanovic, "On the possibilities of using a brushless doubly-fedreluctance generator in a 2 MW wind turbine“, IAS'08 Annual Meeting, IEEE.

[10] A. Schramm andD. Gerling, "Researches on the suitability of switched reluctance machines and permanent magnet machines for specific aerospace applications demanding fault tolerance“, in: SPEEDAM 2006 Proc., 23-26 May 2006, pp. 56-60.

[11] A. G. Jack, B. C. Mecrow, and J. A. Haylock, "Acomparative study of permanent magnet and switchedreluctance motors for high-performance fault-tolerant applications“ IEEETrans. On Industry Applications, vol. 32, No. 4, July/August 1996

[12] A. M. Omekanda, B. Lequesne, H. Klode, S. Gopalakrishnan, and I. Husain, "Switched reluctance versus permanent magnet", IEEE Industry Applications Magazine, July/August 2009.

[13] H. A. Toliyat, "Recent advances and applications of power electronics and motor drives- electric machines and motor drives“, IECON'2008, $34^{\text {th }}$ Annual Conf. Of IEEE, 10-13 Nov. 2008, pp. 34-36.

[14] V. K. Sharma, M.A.Khan, B. Singh and S. S. Murthy, "Comparison of power quality aspects of switched reluctance and permanent magnet brushless DC motor“, in: Proc. Of TENCON'2000, vol.3, pp. 300-303.

[15] A.Vagati, A. Fratta, G. Franceschini, P. Rosso, "AC motors for highperformance drives: a design-based comparison", IEEE Trans. on IA,vol. 32, no. 5, pp. 1211-1219, Sepy./Oct. 1996.

[16] V. B. Honsinger, "Sizing equations for electrical machinery",IEEE Trans. on Energy Conversion, vol. 2, no. 1, pp. 116-121, March 1987.

[17] S. Huang, J. Luo, F. Leonardi, and T. A. Lipo, “A General Approach to Sizing and Power DensityEquations for Comparison of Electrical Machines", On Industry Applications, vol. 34, no. 1, pp. 92-97, January/February 1998.

[18] S. Huang, M. Aydin, T.A. Lipo, "A Direct Approach to Electrical Machine Performance Evaluation: Torque Density Assessment and Sizing Optimization", ICEM 2002, Art. 235, Belgium.

[19] R. Krishnan, "Switched reluctance motor drives: modeling, simulation, analysis, design, and applications", Magna Physics Pubishing, 2001.

[20] VKim K.C., Ahn J.S., Won S.H., Hong J.P., Lee J., "A study on the optimal design of SynRM for the high torque and power factor", IEEE Transactions on Magnetics, vol. 43, no. 6, pp. 2543-2545, June 2007. 